Research Article

\section{Curettage is a risk factor for}

\section{marginal umbilical cord insertion}

\section{Elie Nkwabong ${ }^{1 *}$, Simon Junior Mabol Mbeleck ${ }^{2}$ and Florence Tumasang $^{3}$}

${ }^{1} \mathrm{MD}$, Associate Professor, Obstetrician \& Gynecologist, Department of Obstetrics and Gynecology, Faculty of Medicine and Biomedical Sciences, University Teaching Hospital, Yaoundé, Cameroon ${ }^{2} \mathrm{MD}$, Higher Institute of Medical Technology, Yaoundé, Cameroon

${ }^{3} \mathrm{MD}$, Assistant Lecturer, Obstetrician \& Gynecologist, Higher Institute of Medical Technology, Yaoundé, Cameroon

\section{Abstract}

Objective: To identify the risk factors for marginal cord insertion (MCI)

Material and Methods: This case-control study was carried out between $1^{\text {st }}$ February and $30^{\text {th }}$ June 2019. Singletons with and without $\mathrm{MCl}$ at delivery were recruited. Main variables analyzed included maternal age, parity, number of previous dilatation and curettage (D\&C) or manual vacuum aspiration (MVA), time interval between each procedure and conception, cord insertion. Fisher's exact test, t-test and logistic regression were used to compare data from both groups.

Results: We found 60 cases of $\mathrm{MCl}(4.1 \%)$. The significant $(p<0.05)$ risk factors for $\mathrm{MCl}$ were past-history of D\&C (aOR 5.97, 95\% Cl 1.95-18.25) particularly when conception occurred $<5$ months after D\&C (OR 10.5, 95\% Cl 1.36-81.05), fetal female sex (aOR 3.82, 95\% Cl 1.4110.32), parity $\geq 4$ (aOR $2.63,95 \% \mathrm{Cl} 1.05-12.71$ ) and past-history of MVA (aOR $2.06,95 \% \mathrm{Cl}$ 1.23-8.76).

Conclusion: Women should be advised to conceive at least five months after D\&C

\section{More Information}

*Address for Correspondence: Elie Nkwabong, Associate Professor, Obstetrics \& Gynecology, P.O. Box 1364 Yaoundé, Cameroon, Tel: (237) 699663843; Fax: (237) 222312567; Email: enkwabong@yahoo.fr

Submitted: 10 December 2019

Approved: 01 July 2020

Published: 02 July 2020

How to cite this article: Nkwabong E, Mbeleck SJM, Tumasang F. Curettage is a risk factor for marginal umbilical cord insertion. Clin J Obstet Gynecol. 2020; 3: 081-084.

DOI: 10.29328/journal.cjog.1001054

Copyright: @ 2020 Nkwabong E, et al. This is an open access article distributed under the Creative Commons Attribution License, which permits unrestricted use, distribution, and reproduction in any medium, provided the original work is properly cited.

Keywords: Marginal umbilical cord insertion; Risk factors; Dilatation and curettage; Fetal female sex; Manual vacuum aspiration

W) Check for updates

OPEN ACCESS

\section{Introduction}

Marginal cord insertion (MCI) is defined as the insertion of the umbilical cord within a distance of $<3 \mathrm{~cm}$ from the placental margins [1]. For others, the cord is said to be marginally inserted when the distance between the external margin of the umbilical cord and that of the placenta is less than $2 \mathrm{~cm} \mathrm{[2,3].} \mathrm{The} \mathrm{prevalence} \mathrm{of} \mathrm{MCI} \mathrm{varies} \mathrm{between} 6.3 \%$ and $7 \%$ in singleton pregnancies $[1,4,5]$.

The umbilical cord insertion site to the placenta can be central, lateral, marginal or velamentous. Central and lateral umbilical cord insertions, categorized as normal, represent more than $90 \%$ of cord insertions of term placentas [1]. Velamentous and marginal cord insertions are categorized as abnormal.

The pathogenesis of MCI is not well known. It is thought to result from abnormal primary implantation or 'polarity theory' [5]. Another theory is the 'trophotropism theory' which postulates that the placenta grows in areas with good blood supply and atrophies in areas where blood supply is poor [5]. The last theory is the 'abnormal placental development because of decreased chorionic vessel branching theory'. According to this theory, MCI results from abnormal vasculogenesis in the placenta.

MCI can be diagnosed ultrasonographically as from the $18^{\text {th }}$ week of gestation [6]. MCI is associated with adverse maternal and especially perinatal outcomes. There is a strong association between $\mathrm{MCI}$ and intrauterine growth retardation (IUGR), preeclampsia, nuchal cord entanglement, antepartum hemorrhage from placenta abruption or placenta praevia, increased risk of cesarean section (CS), low birth weight (LBW), poor Apgar score and transfer of newborn to neonatal intensive care unit (NICU) $[1,4,7,8]$.

There is scarcity of papers on risk factors for MCI in the literature. Known risk factors for MCI are advanced 
maternal age ( $\geq 35$ years), chronic maternal diseases (chronic hypertension, asthma and diabetes), female fetus, assisted reproductive technology and previous CS [4].

The effect of various endometrial insults on the pathogenesis of MCI has not yet been evaluated. Some other risk factors might exist. Knowing the risk factors for MCI might help in the prevention or in the diagnosis of some cases. To the best our knowledge, no study has evaluated the risk factors for MCI in a developing country. Hence this study which aimed at identifying these risk factors.

\section{Methods}

This case-control study was carried out between $1^{\text {st }}$ February and 30 $30^{\text {th }}$ June 2019 in two University Teaching Hospitals. All singletons with MCI at delivery ( $\geq 28$ complete weeks) were recruited as cases. For each case, the three singletons delivered immediately after the case without MCI were recruited as controls. A written informed consent was obtained from each woman or from their relatives. This study was approved by the institutional ethics committee.

The variables recorded on a pre-established questionnaire included maternal age at delivery, parity, tobacco or alcohol consumption, number of previous dilatation and curettage (D\&C) or manual vacuum aspiration (MVA), time interval between D\&C or MVA and conception, past history of CS, chronic hypertension (blood pressure $\geq 140 / 90 \mathrm{mmHg}$ before pregnancy or before 20 weeks' gestation or both), overt diabetes (fasting blood sugar $>125 \mathrm{mg} / \mathrm{dl}$ ), gestational age at delivery (confirmed by an ultrasound scan performed before 20 weeks of gestation), mode of delivery, cord insertion (MCI was defined in this survey as the insertion of the umbilical cord with its external margin at less than $2 \mathrm{~cm}$ from that of the placenta $[2,3]$.

The necessary minimum sample size was calculated as needing at least 50 cases of $\mathrm{MCI}$, using the following formula:
$\mathrm{N}=2 \times(\mathrm{Z} \alpha+\mathrm{Z} \beta / \mathrm{P} 0-\mathrm{P} 1)^{2} \times \mathrm{P} \times(1-\mathrm{P})$, where $\mathrm{Z} \alpha=1.96$ corresponds to a type I error of $2.5 \%, \mathrm{Z} \beta=1.96$ corresponds to a type II error of $2.5 \%$ or a power of $97.5 \%$, P0 the prevalence of placenta abruption amongst women with MCI $(29.6 \%)^{9}$, P1 the prevalence of placenta abruption amongst women without MCI $(1.2 \%)^{9}$ and $\mathrm{P}$ is $(\mathrm{P} 0+\mathrm{P} 1) / 2$. To increase the power of our study, we decided to recruit three controls for each case.

Data were analyzed using SPSS 21.0 (IBM Corp., Armonk, NY, USA). Data of women whose newborns presented MCI were compared to those without MCI. Fisher's exact test was used to compare categorical variables and t-test to compare continuous variables. We used odds ratio (OR) with their $95 \%$ confidence intervals (CIs) to present the comparison between the two groups. Logistic regression was used to control for confounders. $p<0.05$ was considered statistically significant.

\section{Results}

During the study period, we had a total of 60 cases of MCI out of 1470 singleton deliveries, given a prevalence of $4.1 \%$. As controls, 180 newborns without MCI were recruited. Some sociodemographic and obstetrical variables of the study population are given in table 1 .

Women of parity $\geq 4$ were more found amongst cases than amongst controls ( 10 or $16.7 \%$ vs. 6 or $3.3 \%$, OR $5.80,95 \%$ CI 2.01-16.74, $p=0.001$ ). Parity $\geq 4$ remained a risk factor for $\mathrm{MCI}$ even after adjustment for confounding factor.

As concerns occupation, civil servant was also more found amongst cases than amongst controls at univariate analysis (19 or $31.7 \%$ vs. 31 or $17.2 \%$, OR $2.22,95 \%$ CI $1.14-4.32, p$ $=0.015)$, but it was not associated with MCI at multivariate analysis.

Mean gestational age at delivery was $38.8 \pm 1.0(36-42)$ in the MCI group vs. $38.9 \pm 1.1$ (33-42) in the control group ( $p$ $=0.533$ ). Nevertheless, mean birth weight was lower in the

Table 1: Some sociodemographic characteristics of the population under study.

\begin{tabular}{|c|c|c|c|c|c|c|}
\hline \multicolumn{2}{|l|}{ Variables } & $\begin{array}{c}\text { Pregnant women }(n=60) \\
\text { with } \mathrm{MCI} N(\%)\end{array}$ & $\begin{array}{l}\text { Pregnant women }(n=180) \text { without } \mathrm{MCI} \\
\qquad \mathrm{N}(\%)\end{array}$ & OR & $95 \% \mathrm{Cl}$ & $p$ - value \\
\hline \multicolumn{2}{|l|}{ Maternal age $(y)$} & $27.8 \pm 3.6(18-35)$ & $26.1 \pm 4.6(16-40)$ & - & - & 0.009 \\
\hline \multicolumn{2}{|l|}{ Parity } & $1.8 \pm 0.9(1-5)$ & $1.9 \pm 1.4(0-12)$ & - & - & 0.604 \\
\hline \multirow{2}{*}{ Maternal age $(y)$} & $\geq 30$ & $18(30.0)$ & $38(21.1)$ & \multirow{2}{*}{1.60} & \multirow{2}{*}{$0.82-3.09$} & \multirow{2}{*}{0.109} \\
\hline & $<30$ & $42(70.0)$ & $142(78.9)$ & & & \\
\hline \multirow{2}{*}{ Number of MVA* } & $\geq 2$ & $3 / 49(6.1)$ & 3/170 (1.7) & \multirow{2}{*}{3.63} & \multirow{2}{*}{$0.71-18.59$} & \multirow{2}{*}{0.127} \\
\hline & $\leq 1$ & 46/49 (93.9) & $167 / 170(98.3)$ & & & \\
\hline \multirow{2}{*}{ Number of $D \& C^{* *}$} & $n=2$ & 9/47 (19.1) & $7 / 162(4.3)$ & \multirow{2}{*}{5.24} & \multirow{2}{*}{$1.83-14.97$} & \multirow{2}{*}{0.002} \\
\hline & $n \leq 1$ & $38 / 47(80.9)$ & $155 / 162(95.7)$ & & & \\
\hline \multirow{2}{*}{ Previous mode of delivery } & CS & $9(15)$ & $19(10.5)$ & \multirow{2}{*}{1.49} & \multirow{2}{*}{$0.63-3.51$} & \multirow{2}{*}{0.238} \\
\hline & VD & $51(85)$ & $161(89.4)$ & & & \\
\hline \multirow{2}{*}{ Fetal sex } & Female & $44(73.3)$ & $98(54.4)$ & \multirow{2}{*}{2.30} & \multirow{2}{*}{$1.20-4.37$} & \multirow{2}{*}{0.007} \\
\hline & Male & $16(26.7)$ & $82(45.6)$ & & & \\
\hline \multirow{2}{*}{ Birth weight $(\mathrm{g})$} & $<3000$ & $20(33.3)$ & $8(4.4)$ & \multirow{2}{*}{10.75} & \multirow{2}{*}{$4.41-26.15$} & \multirow{2}{*}{$<0.001$} \\
\hline & $\geq 3000$ & $40(66.7)$ & $172(95.6)$ & & & \\
\hline \multirow{2}{*}{ Placenta weight } & $<600$ & $56(93.3)$ & $92(51.1)$ & \multirow{2}{*}{13.39} & \multirow{2}{*}{$4.65-38.48$} & \multirow{2}{*}{$<0.001$} \\
\hline & $\geq 600$ & $4(6.7)$ & $88(48.8)$ & & & \\
\hline
\end{tabular}


MCI group than in the control group: $2986.9 \pm 161.0 \mathrm{~g}$ (2600$3560) v s .3198 .4 \pm 219.3 \mathrm{~g}(2200-3850), p<0.0001$.

Mean placenta weight was also significantly lower in the MCI group $(551.1 \pm 52.6 \mathrm{~g}$, range $480-700$ vs. $614.9 \pm 68.9$, range $360-800, p<0.0001$ ).

Newborns of women aged 30 to 34 were at risk of MCI (17 or $28.3 \%$ vs. 27 or $15 \%$, OR 2.24, 95\% CI 1.11-4.48, $p=0.019$ ), but those of women aged between 20 and 24 were protected (5 or $8.4 \%$ vs. 55 or $30.4 \%$, OR 0.20 , 95\% CI $0.08-0.54$, $p=0.0002)$.

We found no association between previous mode of delivery and MCI. Also, no association was found between overt diabetes, chronic hypertension, placenta insertion, tobacco or alcohol consumptions and MCI (Table 2).

As concerns the 60 women of the MCI group, past history of D\&C was found amongst 11 of them and past history of MVA amongst 13 , as against 36 who had no past history of these two procedures. In the control group, amongst the 180 women, 10 had past history of D\&C, 18 past history of MVA as against 152 with no past history of these two procedures.

Past history of D\&C (amongst women with no past history of MVA) was a risk factor for MCI $(11 / 47$ or $23.4 \%$ vs. $10 / 162$ or $6.1 \%$, OR 4.64, 95\% CI 1.83-11.77, $p=0.001$ ). The risk of MCI increased with the number of D\&C (Table 1). Past history of D\&C was a risk factor for MCI even after adjustment for confounding factors (Table 3). Women whose current pregnancy occurred $<5$ months after the last $\mathrm{D} \& \mathrm{C}$ were more found amongst cases $(9 / 11$ or $81.8 \%$ vs. $3 / 10$ or $30 \%$, OR $10.5,95 \%$ CI 1.36-81.05, $p=0.024$ ).

We also found that women with past history of MVA (amongst women with no past history of D\&C) were at risk for MCI (13/49 or $26.5 \%$ vs. $18 / 170$ or $10.6 \%$, OR $3.05,95 \%$ CI $1.36-6.79, p=0.007)$. Contrarily to $\mathrm{D} \& \mathrm{C}$, women who conceived $<5$ months after MVA were not more at risk than those who conceived $\geq 5$ months after $(9 / 13$ or $69.2 \% v$ s. $12 / 18$ or $66.7 \%$, OR $1.12,95 \%$ CI $0.24-5.20, p=0.597$ ).

Protective factors for MCI were maternal age between 20 and 24 years, nulliparity ( 5 or $7.7 \%$ vs. 60 or $31.4 \%$, OR 0.18 , $95 \%$ CI $0.07-0.47, p<0.0001)$, absence of D\&C (OR 0.21, 95\% CI $0.08-0.54, p=0.001$ ), absence of MVA (OR $0.32,95 \% \mathrm{CI}$ $0.14-0.73, p=0.006$ ) and newborn of male sex (OR $0.43,95 \%$ CI 0.22-0.82, $p=0.007$ ).

\section{Discussion}

Our study found a prevalence of MCI of 4.1\%. Risk factors for MCI were past history of $\mathrm{D} \& \mathrm{C}$, conception $<5$ months after D\&C, fetal female sex, parity $\geq 4$ and past history of MVA.

Our prevalence of MCI was lower than that of 7\% and 7.2\% observed respectively in USA and in our units previously [5,7].

We found no association between MCI and maternal age. Previous studies found maternal age $\geq 40$ as a risk factor for MCI $[4,9]$. The absence of association between $\mathrm{MCI}$ and maternal age might be attributed to the absence of woman aged $\geq 40$ in our study population. We also found also no association between MCI and overt diabetes, chronic hypertension, previous mode of delivery or placenta insertion.

Past history of intrauterine procedures (D\&C or MVA) was a risk factor for $\mathrm{MCI}$ in our series, even after logistic regression. Various insults on the endometrium can lead to its subsequent poor regeneration [10]. In our study, D\&C was riskier than MVA. Consequently, MVA should be preferred to D\&C, as studies showed that MVA was efficient as D\&C for diagnostic procedure in women with abnormal uterine bleeding [11]. Furthermore, D\&C is more traumatizing than MVA [12]. Women with past history of two D\&C were more at risk. This is in accordance with the findings of some authors who observed gradual endometrium thinning with repeated D\&C [13].

Table 2: Distribution of some other variables amongst the study population.

\begin{tabular}{|c|c|c|c|c|c|}
\hline Variables & $\begin{array}{l}\text { Pregnant women with } \mathrm{MCI}(n=60) \\
\mathrm{N}(\%)\end{array}$ & $\begin{array}{l}\text { Pregnant women without MCI }(n=180) \\
\text { N (\%) }\end{array}$ & OR & $95 \% \mathrm{CI}$ & $p$ - value \\
\hline Overt diabetes & $2(3.3)$ & $4(2.2)$ & 1.51 & $0.27-8.49$ & 0.467 \\
\hline Chronic hypertension & $5(8.3)$ & $12(6.7)$ & 1.27 & $0.42-3.77$ & 0.426 \\
\hline Placenta Praevia & $2(3.3)$ & $5(2.8)$ & 1.20 & $0.22-6.38$ & 0.557 \\
\hline Alcohol consumption & $1(1.7)$ & $16(8.9)$ & 0.17 & $0.02-1.33$ & 0.079 \\
\hline Tobacco consumption & $0(0)$ & $4(2.2)$ & - & - & 0.314 \\
\hline
\end{tabular}

Table 3: Independent risk factors for $\mathrm{MCl}$.

\begin{tabular}{|c|c|c|c|c|c|c|}
\hline Risk factors & OR & $95 \% \mathrm{Cl}$ & $p$ - value & aOR & $95 \% \mathrm{Cl}$ & $p$ - value \\
\hline Past history of D\&C & 4.64 & $1.83-11.77$ & 0.001 & 5.97 & $1.95-18.25$ & 0.002 \\
\hline Female sex & 2.30 & $1.20-4.37$ & 0.007 & 3.82 & $1.41-10.32$ & 0.008 \\
\hline Parity $\geq 4$ & 5.80 & $2.00-16.74$ & 0.001 & 2.63 & $1.05-12.71$ & 0.029 \\
\hline Past history of MVA & 3.05 & $1.36-6.79$ & 0.007 & 2.06 & $1.23-8.76$ & 0.039 \\
\hline Maternal age $30-34$ & 2.24 & $1.11-4.48$ & 0.019 & 2.28 & $0.87-5.98$ & 0.092 \\
\hline Civil servant & 2.22 & $1.14-4.34$ & 0.015 & 1.69 & $0.65-4.33$ & 0.274 \\
\hline
\end{tabular}

MCI: Marginal Cord Insertion; OR: Odds Ratio; Cl: Confidence Interval; aOR: adjusted OR; D\&C: Dilatation \& Curettage; MVA: Manual Vacuum Aspiration 
During D\&C, there might have been some foci of endometrial destruction. Thereafter, the endometrium might not have regenerated completely before the next conception, especially if the conception occurred within the four months that followed D\&C. Some studies observed that the endometrium is only appropriate for normal reproductive function six months after D\&C, the extent of the damage to endometrial function not found to be reflected by the endometrial thickness only [14].

In the cases of conception within the four months that followed D\&C, some areas of the endometrium might not have been appropriate for placenta development. This might lead to asymmetrical placenta development from the point of cord insertion, the placenta being less developed where the endometrium is not well regenerated, leading to reduced placenta development. Indeed, the mean placenta weight was significantly low amongst cases. Histological examinations of the placentas were not done, giving that for cultural reasons many women took it back immediately to bury it. Examination might have visualized the suspected placental anomalies.

The risk of MCI was reduced amongst women who conceived at least five months after D\&C. Therefore, women should be advised to conceive at least five months after this procedure.

Fetal female sex was a risk factor for $\mathrm{MCI}$ in our study even after adjustment for confounding factors, as observed by some authors [4]. The explanation is unknown. Studies should be carried out to explain this association.

Finally, fetuses of women with parity $\geq 4$ were also at risk of MCI even after multivariate analysis. This might be attributed to successive deliveries of the placentas. There might exist some foci of endometrial injury during placental separation (perhaps due to foci of morbidly adherent placenta, for instance placenta accreta) and probably subsequent poor regeneration of the endometrium, with subsequent asymmetrical development of the placenta, as already explained above. More studies should be carried out to confirm these assertions.

The limitations of our study are our small sample size and the absence of women aged 40 in our series. Furthermore, we could not do histologic examination of the placentas. More studies with larger sample size should be carried out to confirm these risk factors and to look for others.

\section{Conclusion}

Risk factors for $\mathrm{MCI}$ in our series were past history of D\&C, fetal female sex, parity $\geq 4$ and past history of MVA. Therefore, MVA and especially D\&C should be avoided as much as possible. MVA should substitute D\&C for intra-uterine procedures. Moreover, if $\mathrm{D} \& \mathrm{C}$ is performed, women should be advised to conceive at least five months after the procedure. Lastly, $2^{\text {nd }}$ trimester ultrasound scan should emphasize on the umbilical cord insertion amongst women with the abovementioned risk factors for MCI.

\section{References}

1. Luo G, Redline RW. Peripheral insertion of umbilical cord. Pediatr Dev Pathol. 2013; 16: 399-404.

PubMed: https://www.ncbi.nlm.nih.gov/pubmed/24020823

2. Brouillet S, Dufour A, Prot F, Feige JJ, Equy V, et al. Influence of the umbilical cord insertion site on the optimal individual birth weight achievement. Biomed Res Int. 2014; 43: 1-8.

3. Sun J, Wang L, Li Y. Clinical value of color doppler ultrasound in prenatal diagnosis of umbilical cord entry abnormalities. Pak J Med Sci. 2016; 32: 1414-1418.

PubMed: https://www.ncbi.nlm.nih.gov/pubmed/28083036

4. Ebbing C, Kiserud T, Johnsen SL, Albrechtsen S, Rasmussen S Prevalence, Risk Factors and Outcomes of Velamentous and Marginal Cord Insertions: A Population-Based Study of 634,741 Pregnancies. PLoS ONE. 2013; 8: e70380.

PubMed: https://pubmed.ncbi.nIm.nih.gov/23936197/

5. Baergen RN. Umbilical Cord Pathology. Surg Pathol Clin. 2013; 6: 61-85.

6. Padula $F$, Laganà $A$, Vitale $S$, Mangiafico $L$, D'Emidio $L$, et al Ultrasonographic evaluation of placental cord insertion at different gestational ages in low-risk singleton pregnancies: a predictive algorithm. Facts Views Vis ObGyn. 2016; 8: 3-7.

PubMed: https://www.ncbi.nlm.nih.gov/pmc/articles/PMC5096422/

7. Nkwabong E, Ndoumbe Mballo J, Dohbit JS. Risk factors for nuchal cord entanglement at delivery. Int J Gynecol Obstet. 2018; 141: 108-112. PubMed: https://pubmed.ncbi.nlm.nih.gov/29215708

8. Ismail KI, Hannigan A, O'Donoghue K, Cotter A. Abnormal placental cord insertion and adverse pregnancy outcomes: a systematic review and meta-analysis. Syst Rev. 2017; 6: 242.

PubMed: https://pubmed.ncbi.nlm.nih.gov/29208042/

9. Nkwabong E, Njikam F, Kalla G. Outcome of pregnancies with marginal umbilical cord insertion. J Matern Fetal Neonatal Med. 2019: 17: 1-5. PubMed: https://pubmed.ncbi.nlm.nih.gov/31164018/

10. Li L, Shi J, Zhang QF, Yan J, Yan LY, et al. Effect of curettage and copper wire on rabbit endometrium: a novel rabbit model of endometrial mechanical injury. Chin Med J (Engl). 2011; 124: 1708-1713. PubMed: https://www.ncbi.nlm.nih.gov/pubmed/21740782

11. Sirimai K, Lertbunnaphong T, Malakorn K, Warnnissorn M. Comparison of Endometrial Pathology between Tissues Obtained from Manual Vacuum Aspiration and Sharp Metal Curettage in Women with Abnormal Uterine Bleeding. J Med Assoc Thai. 2016; 99: 111-118. PubMed: https://www.ncbi.nlm.nih.gov/pubmed/27249889

12. Choobun T, Khanuengkitkong S, Pinjaroen S. A comparative study of cost of care and duration of management for first-trimester abortion with manual vacuum aspiration (MVA) and sharp curettage. Arch Gynecol Obstet. 2012; 286: 1161-1164.

PubMed: https://www.ncbi.nlm.nih.gov/pubmed/22684851

13. Azumaguchi A, Henmi H, Ohnishi H, Endo T, Saito T. Role of dilatation and curettage performed for spontaneous or induced abortion in the etiology of endometrial thinning. J Obstet Gynaecol Res. 2017; 43: 523-529.

PubMed: https://pubmed.ncbi.nlm.nih.gov/28127830/

14. Ozgur K, Bulut H, Berkkanoglu M, Basegmez FO, Coetzee K. Sixmonth recovery needed after dilation and curettage ( $D$ and $C$ ) for reproductive outcomes in frozen embryo transfer. J Obstet Gynaecol. 2018; 38: 1150-1157

PubMed: https://pubmed.ncbi.nlm.nih.gov/29884088 